\title{
85702 - SATISFAÇÃO SEXUAL E 0 USO DE PRESERVATIVO EM INDIVÍDUOS FREQUENTADORES DE UM CENTRO DE CONVIVÊNCIA PARA IDOSOS NO MUNICÍPIO DE CHAPECÓ-SC
}

\author{
Pôster - Gerontologia
}

\author{
Carlos Reinoldo Britzke Brandão / Brandão, CRB / UNOCHAPECÓ; Jaqueline Dall'Agnol / Dall'Agnol, J / \\ UNOCHAPECÓ; Juliano Brustolin / Brustolin, J / UNOCHAPECÓ
}

Introdução: Por muito tempo, envelhecer foi considerado sinônimo de fragilidade, adoecimento e diminuição da autonomia, com a mudança no perfil demográfico passou-se a valorizar mais essa fase da vida ${ }^{1}$. O sexo nessa fase é tão importante quanto na juventude, pois proporciona prazer e sensação de bem-estar². Mas, alguns hábitos de risco como a não utilização de preservativos os expõem a doenças ${ }^{3}$. Logo faz-se necessário políticas públicas voltadas para a saúde sexual deste público, uma vez que atualmente algumas ações e programas são insuficientes ${ }^{4}$. Objetivo: Identificar o nível de satisfação e insatisfação sexual e o uso de camisinha em idosos frequentadores de um centro de convivência. Métodos: Estudo é descritivo do tipo transversal, analisou 80 idosos com idade $>$ ou igual a 60 anos. Os dados foram obtidos através de um protocolo conforme as variáveis relevantes para a pesquisa, como idade, sexo, uso de camisinha, satisfação sexual, no de parceiros. A análise e interpretação dos dados foi feita no software SPSS versão 20,0. O estudo foi aprovado pelo CEP/UNOCHAPECÓ sob número 2.841.123. Os idosos assinaram um termo de consentimento livre e esclarecido. Resultados: (n 80), 78,8\% fem. A idade média foi 69,79 anos $\pm 5,9$. $71,3 \%$ estão sexualmente satisfeitos, $18,8 \%$ insatisfeitos. $57,5 \%$ possuem um parceiro, $5 \%$ tem 2 parceiros e $1,3 \%$ possui 3 parceiros. $58,8 \%$ relataram nunca ter usado camisinha, $22,5 \%$ apenas as vezes e 17,5\% usam sempre. Os motivos para não usar camisinha sempre são: ter um parceiro fixo 57,5\%, desconforto 15,1\%. Conclusões: Foi possível perceber que a maior parte dos idosos está satisfeita com a vida sexual, isso leva a refletir sobre o quão relevante e necessário é o desenvolvimento de ações educativas e de saúde pública que abordem os temas relativos à sexualidade.

Referências: 1. BEZERRA, FC; ALMEIDA, MI; NOBREGA-THERRIEN, SM. Estudos sobre envelhecimento no Brasil: revisão bibliográfica. Rev. bras. geriatr. gerontol. v. 15, n. 1, p. 155-167, 2012; 2. MEDEIROS, KCS; et al. Avaliação do nível de informação em relação a AIDS/HIV por idosos assistidos no Programa de Saúde da família. Geriatr gerontol. v. 2, n. 2, p. 53-8, 2008; 3. DORNELAS NETO, J; et al. Doenças sexualmente transmissíveis em idosos: uma revisão sistemática. Ciênc. saúde colet. v. 20, n. 12, 2015; 4. ABODERIN, I. Sexual and reproductive health and rights of older men and women: addressing apolicy blind spot. Reproductive Health Matters. v. 22, n. 44, p. 185-190, 2014. 